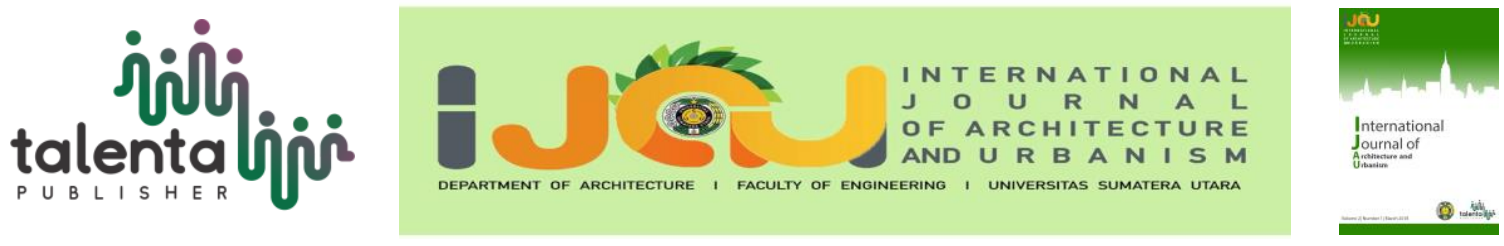

\title{
Medan Amusement Center (Hi-Tech Architecture)
}

\author{
Andalucia $^{1 *}$, Minadiah purba ${ }^{1}$ \\ ${ }^{I}$ Department of Architecture, Universitas Sumatera Utara, Medan, Indonesia
}

\begin{abstract}
From the Central Bureau of Statistics (2014) survey for the happiness index according to the province, North Sumatra is ranked 6th lowest. This data was becoming the basis of the design background of the Medan Amusement Center. Where has, the design in the city becomes a solution due to the distance to the people of Medan for recreation, aims to save time, cost and want to build a city image. Accordingly, the design of the Medan Amusement Center, which located at Jendral Abdul HarisNasution is adjacent to the access to the Kuala Namu International Airport. The design aims to give a new face or Landmark, then the design of the Amusement Center should be an icon for easy to remember. Therefore, the theme applied to the design is High Tech where the theme gives the impression of Futuristic with the use of materials and structures.
\end{abstract}

Keyword: amusement, high-tech, wide-span.

\section{Introduction}

The current technological advances push the routine of society to become very crowded. Moreover, the urban community that in fact very rarely can enjoy the free time that resulted in saturation. Thus, there is an increase in pressure on urban communities that have many problems such as congestion, employment issues, and others. Limitations of spare time are also a problem for urban communities. Medan is the third largest city in Indonesia, after Jakarta and Surabaya, where Medan is gradually becoming a metropolitan city. Therefore, the problems that are common in major cities have occurred in Medan. This is confirmed by the Central Bureau of Statistics (2014) survey for the happiness index according to the province; North Sumatra is ranked 6th lowest. This data makes the city of Medan, who fact is the capital of North Sumatra province experiencing a happiness crisis.

\section{Literature Review}

Theme Park has a more themed function than the playground in general. Because Theme Park presents imagination and fantasy as the basis of its design idea. Theme Park is defined as a 'world' or a place that has features such as not being available in a particular geography, a

*Corresponding author at: Department of Architecture, Faculty of Engineering, Universitas Sumatera Utara,

Jalan Perpustakaan Gedung J07, Medan 20155, Indonesia

E-mail address: andaluciazurdani@gmail.com 
controlled and observable environment, stimulation without stopping. On the inside, there are games that can be used by all circles of visitors, ranging from children to adults [4].

High tech architecture is the design of a building or built environment with certain standards which are then laid out and arranged to solve existing problems, and are achieved by use of an advanced method, both from structural systems, as well as the use of functional and aesthetic building materials. Originally high-tech is the thought of the early 20th century the manifestation is described as a warehouse rack system and factory floor coverings for a home [5]. High Tech Architecture incorporates high-tech industrial elements and technology systems into building design. Hi-tech Architecture is trying to maximize the use of technology that discusses the problem of building characteristics that have a major impact on the resilience of the building itself and its impact on the surrounding environment.

\section{Methodology}

The method used in the design of Medan Amusement Center is a qualitative method. Where a qualitative method is an approach, also called investigative approach because usually researchers collect data by face to face directly and interact with people in place of research [1]. The design starts with the selection of the expected site by with the function of the building. The location is on Jalan Abdul Haris Nasution, Medan Amplas, Medan. Where the location is fairly strategic regarding access to reach the location, to the availability of land that is feasible for building functions.

The theme to be applied is Hi-tech architecture, which will support the building function. Where recreational buildings are ensured to contain facilities that have a heavy mass, will conform to the High-Tech concept of utilizing maximized structure. In addition, an interesting material exposure will also be a visual, conceptual aspect of this building.

\section{Result and Discussion}

Because the applied theme is Hi-tech, the appearance of the building further exposes the texture material (Figure 1). In certain parts, there is also a structure that is exposed to a view for visitors. The application of this theme is not only in the face of the building but also on the inside. There are structures that make the inside more attractive and add a fantastic impression (Figure 2).

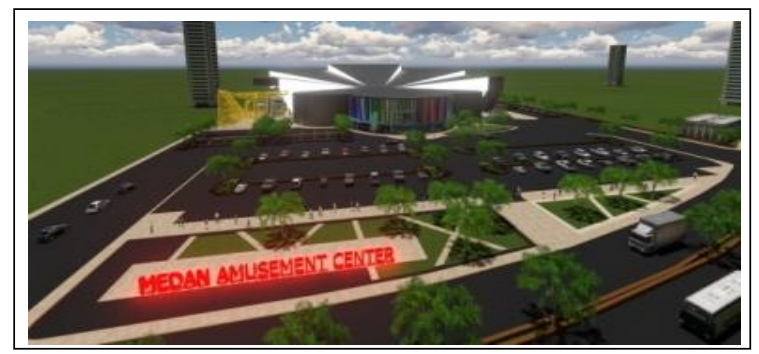

Figure 1. Exterior View 


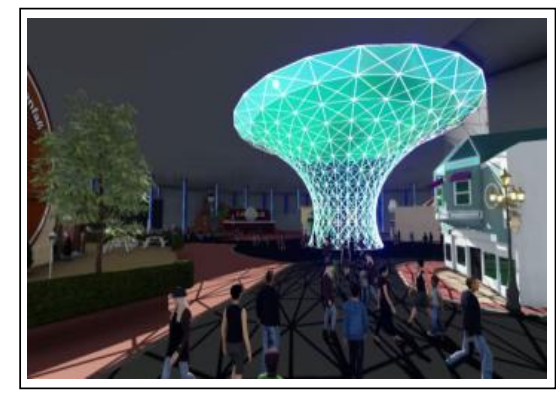

Figure 2. Interior View

Zoning in Medan Amusement Center is divided into 4, i.e., public zone, semi-public zone, personal zone, and service zone (Figure 3). Public zone is in the front of the building, that is pedestrian and garden designed to be outdoor space. This zone can be accessed by anyone, especially pedestrians. Then the semi-private zone, i.e., the parking lot. In this zone, the incoming person is more filtered because of the entrance ticket before entering the parking area. And the private zone is part of the building. In this section is the center of activity in this design.

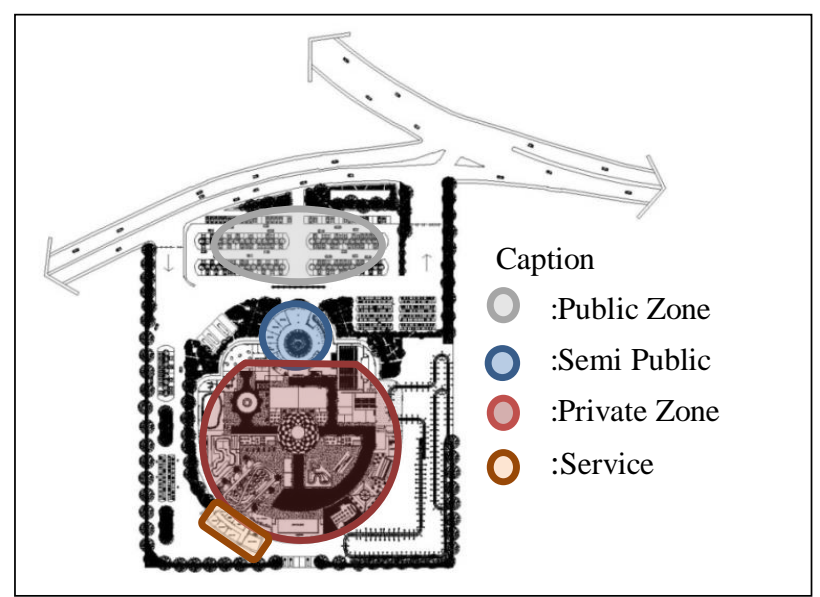

Figure 3. Zoning of Medan Amusement Center

The outer spaces at Medan Amusement Center consist of pedestrian, visitor car parking, visitor motorcycle parking, tourism bus, employee car parking, employee motorcycle parking, parking service (Figure 4). Parking visitors are separated from employee parking so as don't disturb each other. Parking service is at the rear for easy access to the loading dock. For rides, there is a Rollercoaster that connects to the exterior of the building for a high level of extreme taste. The roller coaster extends to the rear of the building. The Rollercoaster structures also add a Hi-Tech impression to the outer space (Figure 5).

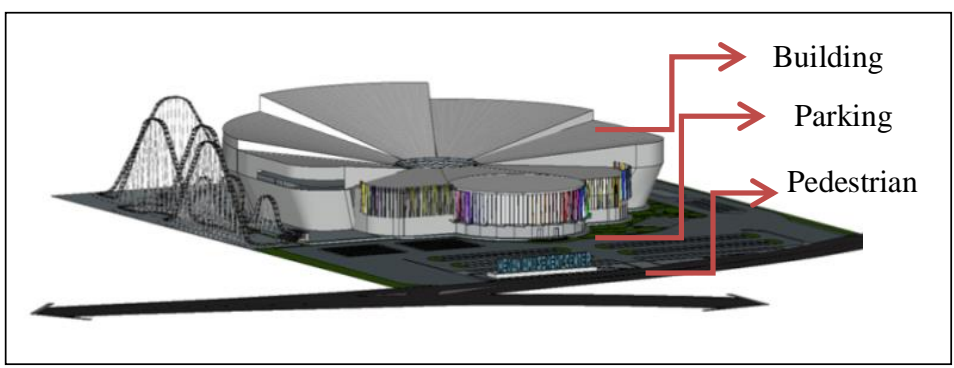

Figure 4. Exterior Zoning 


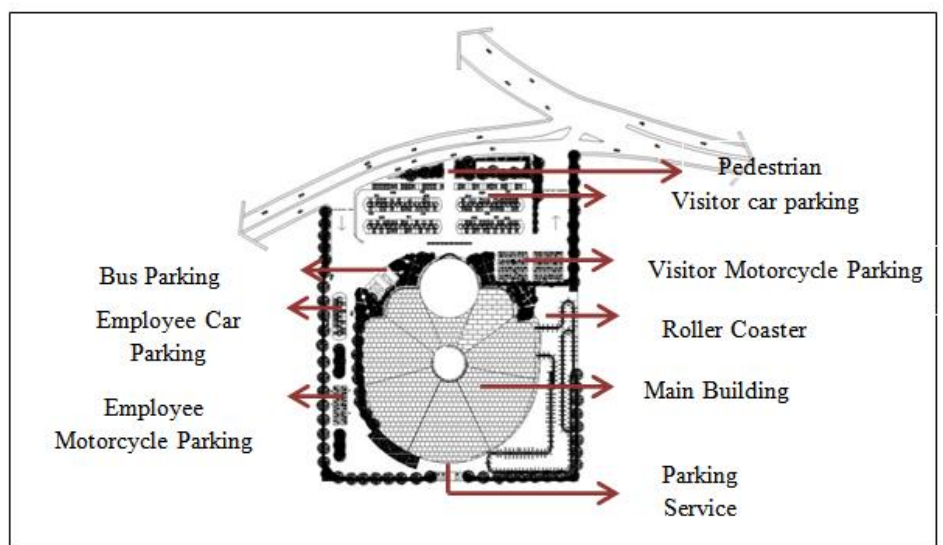

Figure 5. Exterior Area

The concept of space in the Medan Amusement Center is divided into 2, namely the office and entertainment. The office is on the 2 nd floor of the lobby so as not to disturb the visitors and the privacy zone can be more pronounced (Figure 6). Employees access the office through a door in the lobby, which is reserved for employees and employees. Office section there are several rooms, such as employees and employees room, meeting room, restroom, pantry, and others.

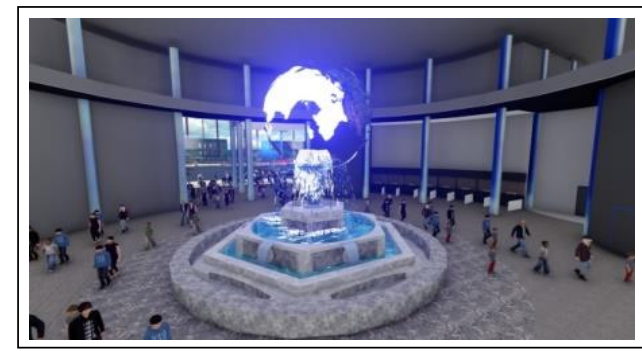

Figure 6. Lobby Scene

In the design of amusement center, there are several standards that must be taken into account, one of which calculation of space that is differentiated according to the age of visitors. Which is divided into 2, namely the space in the outer space and space in the room [3]. For entertainment, there are three concepts of formation of Studio Central, Kid's World, and The Lost City (Figure 7). At Studio Central more emphasis on the value of entertaining it, with the urban view of the 70s that make special interest for visitors. The purpose of the Central Studio is the versatile theater, Science Center, Cinema 4D, Rollercoaster, some gift shop and photo studio (Figure 8).

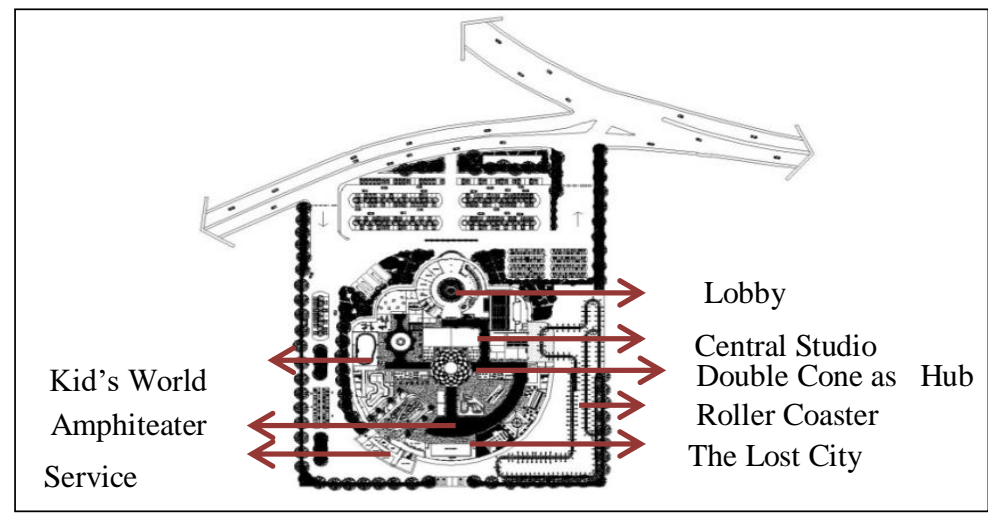

Figure 7. Interior Area 


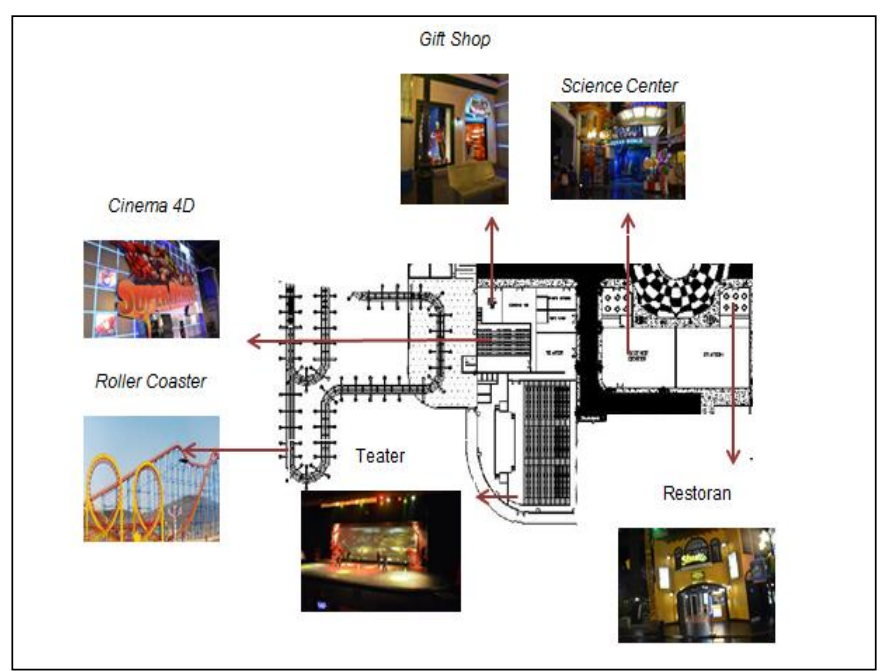

Figure 8. Studio Central

The activity center in this building is centered in a centralized Double Cone structure. The atmosphere in this section feels open and will become the center of entertainment when the carnival arrives. At certain times Double Cone will emit light from the LED lights that are punctured in such a way that they meet the structures that are arranged. Plus the effects of water that sometimes flows up to the effects of fast-moving light from the bottom structure to reach the roof structure can be enjoyed around this Double Cone. Double Cone is surrounded by an artificial garden and sitting area.

Kid's World is a zone reserved for children. Children like to play constructive, collect, exercise, explore, and spend time on entertainment. Then the preparation for the child zone is designed as needed [2]. Kid's World zone is between the zone of Central Studio and The Lost City, so adults who bring children are easier to take care of their children. For adults who want to wait for children, there are cafes and restaurants in the area. In this zone consists of, doll palace, train ride, bumper car, children playground and also equipped with a photo studio (Figure 9).

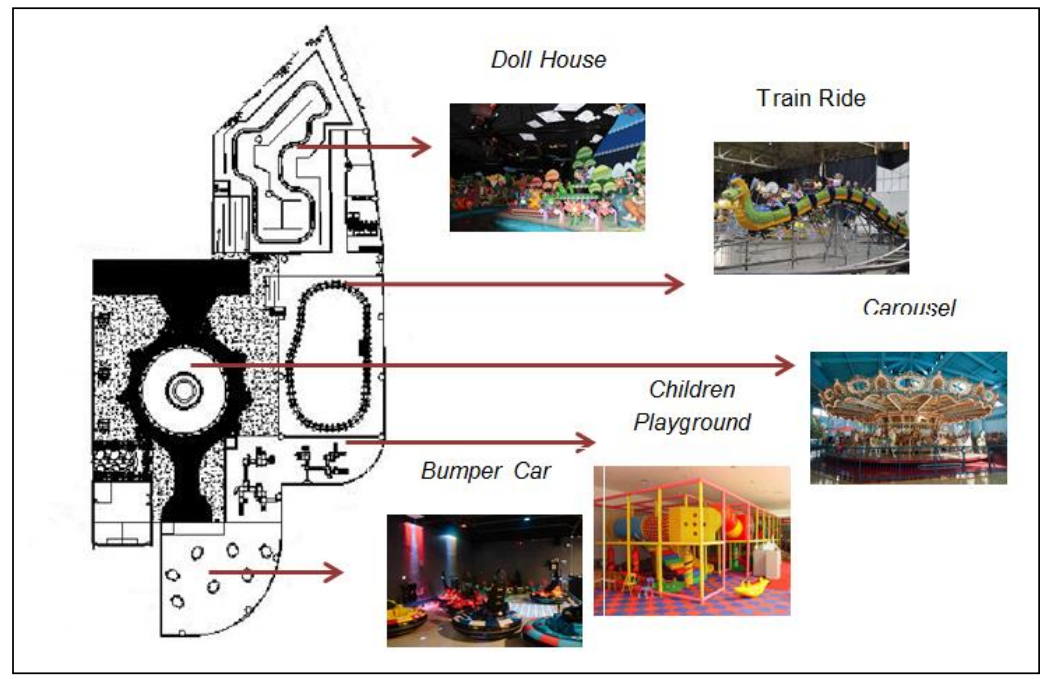

Figure 9. Kid's World 
The Lost City is a magnet in this building. This zone is intended for adults with medium-toextreme rides. This zone is designed with a view of rocks and arid in accordance with the extreme of the rides presented. Rides contained in this zone include; Log Flume Ride, Haunted House, Friss Bee, Wall Climbing, Spin Ride, Drop Tower, Meteor Hammer Ride, and several restaurants as well as cafes. The main attraction is the amphitheater which is an inviting show (Figure 10).

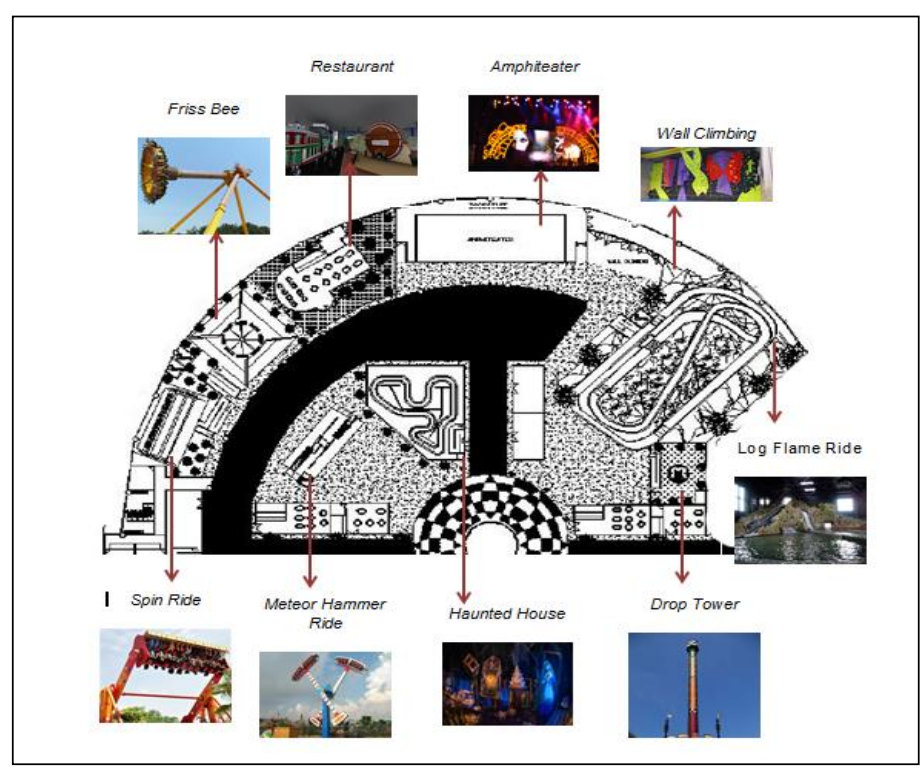

Figure 10. The Lost City

\section{Conclusion}

Medan Amusement center is a place that presents various kinds of various recreational activities that can balance the entertainment facilities in Medan. Being in the center of the city, this building is expected to be a center of positive activity. Therefore this building is somewhat the midpoint between entertainment and economic activities. Located on the side of Jalan Abdul HarisNasution, the location is easily accessible and reached by the people of Medan. With 4.5 ha of land, this building can accommodate various activities that can be targeted market to attract visitors. In this building, there are several themed areas adapted to the interior. In this building, there are several themed areas that are adjusted according to the interior. Such as The Last city which is characterized by trees and rocks that add inviting area. Children's World which is characterized by colorful furniture that seemed pleasant. And Central Studio consisting of several theaters and performances as well as the museum.

This design applies High Tech theme. The use of exposed materials and the structure is shown to be the face of this building. Also, the use of GFRC (Glass fiber reinforced concrete) and LED walls will produce a living impression on the facade of the building. Using Space truss combined with the double cone, characterize the roof of the building. 


\section{Acknowledgment}

This research is part of the requirement to obtain a bachelor's degree in Architecture Departement Universitas Sumatera Utara.

\section{REFERENCES}

[1] J. H. McMillan and S. Schumacher. Research in education: Evidence-based inquiry. Pearson Higher Ed. 2014.

[2] E.. B. Hurlock. Psikologi Perkembangan. Jakarta: Erlangga. 1980.

[3] A. Yoshinobu. Exterior design in architecture. 1981.

[4] M. Sorkin. Variations on a theme park: The new American city and the end of public space. Macmillan. 1992.

[5] J. Kron and S. Slesin. High-tech: the industrial style and source book for the home. Crown Pub. 1978. 